\title{
Gatekeeper war gestern
}

\section{Liebe Leserinnen und Leser,}

in der aktuellen Zukunftsstudie der WHU hat es das Thema Self-Service Reporting klar unter die zehn Themen geschafft, die in den Augen der befragten Finanzvorstände und Controller in fünf Jahren ganz oben auf der Agenda des Controllings stehen werden. Die Erwartungen in diesem Feld sind also unverändert hoch: Seit unserer ersten Befragung zu diesem Themenfeld im Jahre 2012 gehen die Befragten davon aus, dass betriebswirtschaftliche Kennzahlen dem Management in Zukunft ohne größere Einschränkungen, mobil und ganz überwiegend "realtime“ zur Verfügung stehen werden. Interessanterweise hat sich im Ist aber bislang in vielen Unternehmen nur wenig verändert. Woran liegt das? Die Einführung von Self Service ist im operativen Geschäft weniger trivial als auf dem Papier. Und häufig sind die erforderlichen Voraussetzungen - eine akzeptable Datenqualität und eine hinreichende Systemintegration - nicht gegeben. So hat auch unser digitaler Pulse Check erst jüngst gezeigt, dass nur 29 Prozent der befragten Controlling-Leiter die Datenqualität und nur 17 Prozent die Harmonisierung ihrer IT-Systeme für hinreichend hoch halten. Entsprechende Veränderungen sind nicht von heute auf morgen zu haben, sie brauchen einfach Zeit. Dennoch erscheint der Weg vorgezeichnet. Das weitgehend manuelle Erstellen eines Berichts wird über kurz oder lang wegfallen. Die entsprechenden Prozesse werden automatisiert. Und die vielen Controller, die heute in großen Unternehmen in der einen oder anderen Form mit ReportingFragestellungen beschäftigt sind, werden nicht mehr gebraucht - zumindest nicht mehr dafür. Manager haben dann unmittelbaren Zugriff auf betriebswirtschaftliche Daten und können in viel höherem Maße als bislang selbstständig Analysen durchführen. Am Ende verschwindet die traditionelle Rolle des Controllers als Gatekeeper, und seine etablierte Machtposition wird damit zumindest ein Stück weit infrage gestellt. Er muss seine Wertschöpfung nun unmittelbar in der Interaktion von Controller und Manager erbringen.

Aber können Manager überhaupt mit der Vielzahl an Daten umgehen und eigenständig Analysen durchführen? Zeigt nicht die Tatsache, dass einzelne Pioniere des Self Services den

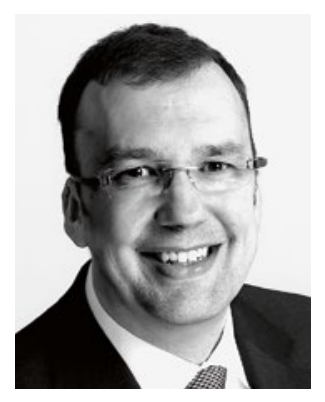

Utz Schäffer

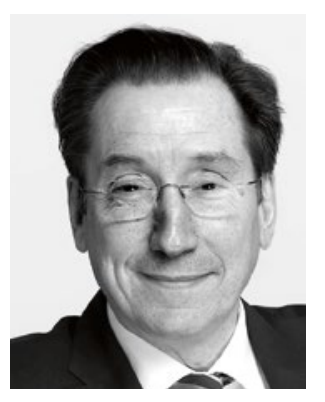

Jürgen Weber bereits abgeschafften Monatsbericht wieder eingeführt haben, dass es so einfach dann doch nicht ist? Wir meinen: Bestimmt kann und soll nicht jeder Manager jede Analyse aus dem Stand übernehmen. Und Ja, ein ergänzender Monatsbericht wird in vielen Unternehmen noch für einige Zeit einen verbindlichen Rahmen und eine gemeinsame Sprache vermitteln. Aber Vorsicht: Heute schon ist der durchschnittliche Manager in Rechnungswesen- und Finanzfragen qualifizierter als noch vor 20 oder 30 Jahren. Standardisierte Apps werden viele Analysen zunehmend einfacher und Managern intuitiv zugänglich machen. Und nicht zuletzt wird die junge, nachwachsende Generation ein restriktives Regime des eingeschränkten Datenzugangs immer weniger akzeptieren. Nimmt man diese Punkte zusammen, wird deutlich, dass Controller umdenken und in der Interaktion mit dem Management signifikant zulegen müssen, wollen sie auch in $\mathrm{Zu}$ kunft noch ausreichend Mehrwert bieten.

Viel Vergnügen bei der Lektüre wünschen Ihnen
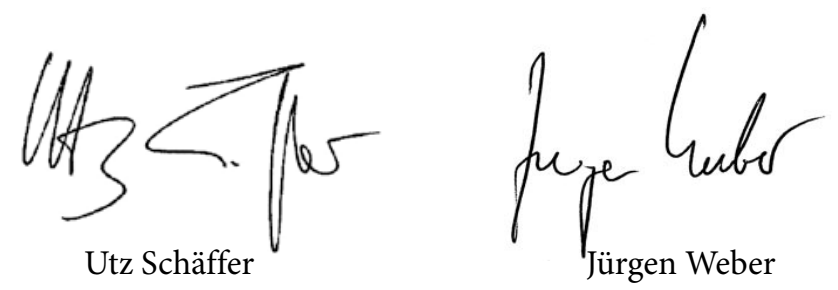